\title{
A chirality-induced alpha phase and a novel molecular magnetic metal in the BEDT-TTF/tris(croconate)ferrate(III) hybrid molecular system
}

\author{
Carlos J. Gómez-García, ${ }^{* a}$ Eugenio Coronado, ${ }^{a}$ Simona Curreli, ${ }^{a}$ Carlos Giménez-Saiz, ${ }^{a}$ Paola Deplano, ${ }^{b}$ \\ Maria Laura Mercuri, ${ }^{* b}$ Luca Pilia, ${ }^{b}$ Angela Serpe, ${ }^{b}$ Christophe Faulmann ${ }^{c}$ and Enric Canadell ${ }^{d}$
}

Received (in Cambridge, UK) 21st July 2006, Accepted 19th September 2006

First published as an Advance Article on the web 5th October 2006

DOI: $10.1039 / \mathrm{b} 610408 \mathrm{~h}$

The novel paramagnetic and chiral anion $\left[\mathrm{Fe}\left(\mathrm{C}_{5} \mathrm{O}_{5}\right)_{3}\right]^{3-}$ has been combined with the organic donor BEDT-TTF $(=\mathrm{ET}=$ bis(ethylenedithio)tetrathiafulvalene) to yield the first chiralityinduced $\alpha$ phase and a paramagnetic metal.

The search for multifunctionality in molecular materials, in particular, the combination of magnetic with electrical properties, is one of the most active areas in molecular science. ${ }^{1}$ Major developments in this field have been the preparation of: (i) the series of paramagnetic superconductors $\mathrm{ET}_{4}\left[\mathrm{H}_{3} \mathrm{OM}^{\mathrm{III}}\left(\mathrm{C}_{2} \mathrm{O}_{4}\right)_{3}\right]$.G $\left(\mathrm{M}^{\mathrm{III}}=\mathrm{Cr}\right.$, Fe and $\left.\mathrm{Ga} ; \mathrm{G}=\mathrm{C}_{6} \mathrm{H}_{5} \mathrm{CN}, \mathrm{C}_{6} \mathrm{H}_{5} \mathrm{NO}_{2} \ldots\right),{ }^{1,2}$ recently enlarged $^{3}$ by some of us with $\mathrm{G}=\mathrm{PhF}$ and $\mathrm{PhBr}$, (ii) the series of metallic ferromagnets $\mathrm{ET}_{3}\left[\mathrm{M}^{\mathrm{II}} \mathrm{Cr}\left(\mathrm{C}_{2} \mathrm{O}_{4}\right)_{3}\right]\left(\mathrm{M}^{\mathrm{II}}=\mathrm{Mn}, \mathrm{Fe}, \mathrm{Co}\right){ }^{4}$ (iii) the antiferromagnetic superconductors $\kappa-\mathrm{BETS}_{2}\left[\mathrm{FeX}_{4}\right](\mathrm{X}=$ $\mathrm{Br}$ and $\mathrm{Cl})^{1}$ and (iv) the field-induced superconductor $\lambda$-BETS $2\left[\mathrm{FeCl}_{4}\right] .{ }^{5}$ A still unexplored modification in the first series is the change of oxalate by other bidentate similar ligands. A potentially very interesting one is the croconate dianion $\left(\mathrm{C}_{5} \mathrm{O}_{5}{ }^{2-}\right.$, Scheme 1), whose coordinating properties, similarities with the oxalate ligand and ability to mediate magnetic interactions have been recently revised. ${ }^{6}$ Here we report the synthesis, $\dagger$ X-ray structure, $\uparrow$ magnetic $\S$ and electrical properties $\uparrow$ and band structure calculations $\|$ of two new radical salts obtained with the recently prepared $^{7}\left[\mathrm{Fe}\left(\mathrm{C}_{5} \mathrm{O}_{5}\right)_{3}\right]^{3-}$ anion and ET. These salts, formulated as $\alpha-\mathrm{ET}_{5}\left[\mathrm{Fe}\left(\mathrm{C}_{5} \mathrm{O}_{5}\right)_{3}\right] \cdot 5 \mathrm{H}_{2} \mathrm{O}$ (1) and $\beta-\mathrm{ET}_{5}\left[\mathrm{Fe}\left(\mathrm{C}_{5} \mathrm{O}_{5}\right)_{3}\right] \cdot \mathrm{C}_{6} \mathrm{H}_{5} \mathrm{CN}$ (2), differ only in the packing motif of the ET molecules and in the solvent molecules. Salts $\mathbf{1}$ and $\mathbf{2}$ are the first examples of radical salts containing the chiral and paramagnetic $\left[\mathrm{Fe}\left(\mathrm{C}_{5} \mathrm{O}_{5}\right)_{3}\right]^{3-}$ anion.

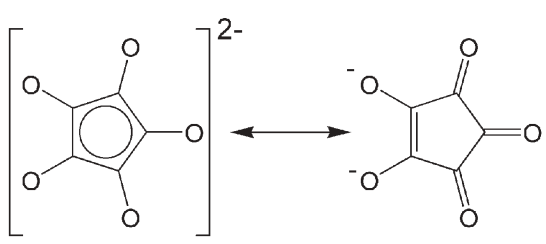

Scheme 1 Croconate dianion.

${ }^{a}$ Instituto de Ciencia Molecular (ICMol) Universidad de Valencia, Pol La Coma s/n, Paterna, (Valencia), 46980, Spain.

E-mail: carlos.gomez@uv.es; Fax:+34963543273

${ }^{b}$ Dipartimento di Chimica Inorganica ed Analitica. Universita di

Cagliari, S.S. 554 - Bivio per Sestu, Monserrato, (Cagliari), I09042, Italy.E-mail:mercuri@unica.it

${ }^{c}$ Equipe Molécules et Matériaux, LCC-CNRS, 205 route de Narbonne, Toulouse, Cedex 04, 31077, France

${ }^{d}$ Institut de Ciencia de Materials (ICMAB), CSIC, Campus de la UAB, Bellaterra, 08193, Spain
Furthermore, salt 1 constitutes, to our knowledge, the first case of a chirality-induced $\alpha$ phase as well as the first example of a pentamerized $\alpha$ phase.

The structuret of $\alpha-\mathrm{ET}_{5}\left[\mathrm{Fe}\left(\mathrm{C}_{5} \mathrm{O}_{5}\right)_{3}\right] .5 \mathrm{H}_{2} \mathrm{O}$ (1) consists of layers of $\mathrm{ET}$ donors in the $b c$ plane alternating with layers of $\left[\mathrm{Fe}\left(\mathrm{C}_{5} \mathrm{O}_{5}\right)_{3}\right]^{3-}$ anions and water molecules (Fig. 1a). The organic layer is formed by parallel stacks of ET molecules along the $c$ direction, with the molecular planes tilted $c a .22^{\circ}$ with respect to the chain direction. Consecutive chains are tilted in opposite senses, giving rise to an $\alpha$ phase (called $\theta_{20}$ by Mori) ${ }^{8}$ (Fig. 1b). Albeit, the ET stacks present a dislocation every five molecules (following the arrangement of the anions), giving rise to the only known $\theta_{51}$ phase in Mori's notation. ${ }^{8}$ The analysis of the bond distances 9 shows that the three crystallographically independent ET molecules (ET1, ET2 and ET3) bear a charge of $+0.3,+0.9$ and +0.9 , respectively, giving a total charge of $3.3 \pm 0.5$, in agreement with the expected value of +3 . Note that ET3 lies about an inversion centre and, therefore, there are two ET1 and ET2 molecules and one ET3 molecule per formula unit. The anionic
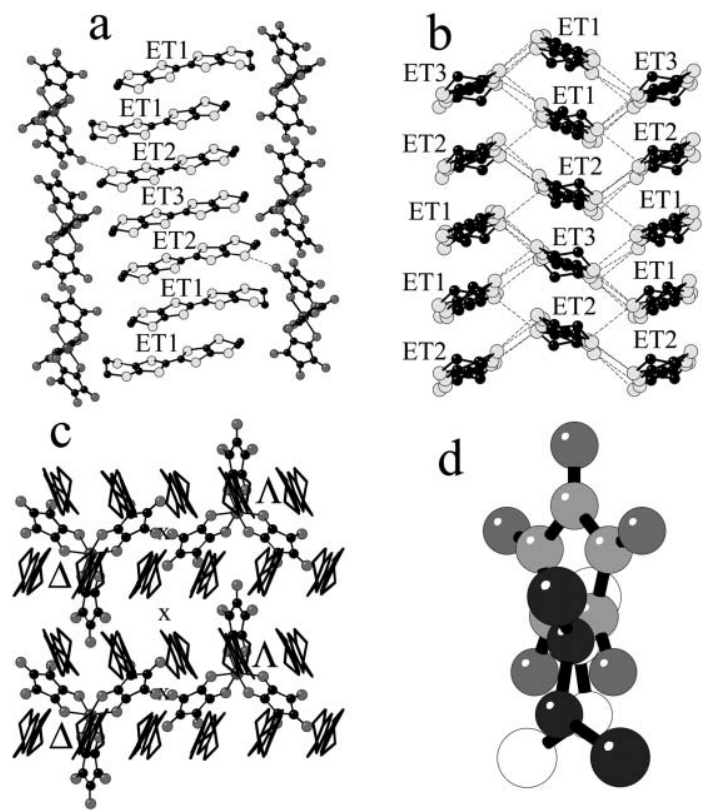

Fig. 1 Structure of 1: (a) View of the alternating cationic and anionic layers. (b) View of the ET layer showing the $\alpha$ packing. (c) View of the anionic layer with the ET molecules above it. The crosses indicate the locations of the inversion centres in the inorganic layer. (d) View of a croconate ring and the terminal $\mathrm{S}$ and $\mathrm{C}$ atoms of the $\mathrm{ET}$ molecules above (black atoms) and below (white atoms). 
layer in $\mathbf{1}$ is formed by isolated $\left[\mathrm{Fe}\left(\mathrm{C}_{5} \mathrm{O}_{5}\right)_{3}\right]^{3-}$ anions (where the $\mathrm{Fe}^{\mathrm{III}}$ ion is surrounded by three croconate ligands acting as 1,2bidentate, with the $\mathrm{Fe}$ ion and one croconate ligand lying on a twofold axis) packed in zigzag rows along the $c$ direction with alternating $\Delta$ and $\Lambda$ chirality (Fig. 1c).

Although the structure is not chiral, the alternation of the chirality of the $\left[\mathrm{Fe}\left(\mathrm{C}_{5} \mathrm{O}_{5}\right)_{3}\right]^{3-}$ anions in $\mathbf{1}$ along the $b$ axis (orthogonal to the ET chains) induces the same kind of alternation in the tilt angles of the ET molecules due to the presence of short anion-donor contacts in this salt. This supramolecular interlayer interaction, together with the steric effects, are clearly evidenced in the interaction between the ET molecules and one of the croconate planes. Thus, each $\Delta$ (or $\Lambda$ ) enantiomer induces a "right-turned" (or left) ET column in the organic layer below and the opposite in the inorganic layer above (Fig. 1c, 1d and synopsis). The disposition of the anions implies that the inversion centre of the organic layer is located above the interchain space (Fig. 1c). As far as we know, the salt $\mathrm{ET}_{9}\left[\mathrm{H}_{4} \mathrm{Co}_{2} \mathrm{Mo}_{10} \mathrm{O}_{38}\right]$ is the only known example of this kind of alternation in the donor stacks induced by the chirality of the anion, ${ }^{10}$ although in this salt the big size of the chiral anion gives rise to alternating ET stacks with a periodicity of three stacks with each orientation $\left(\theta^{33}\right.$ in Mori's notation). ${ }^{8}$

The structuret of $\beta-\mathrm{ET}_{5}\left[\mathrm{Fe}\left(\mathrm{C}_{5} \mathrm{O}_{5}\right)_{3}\right] \cdot \mathrm{C}_{6} \mathrm{H}_{5} \mathrm{CN}$ (2) is very similar to that of 1 (Fig. 2a). The main difference is the packing of the organic layer since the molecular planes of consecutive stacks are parallel, giving rise to a $\beta$ phase (Fig. 2b). ${ }^{11}$ The analysis of the bond distances ${ }^{9}$ also shows an inhomogeneous charge distribution, with charges of $+1.2,+0.9,+0.1,+0.8$ and +0.4 for the five crystallographically independent ET molecules (ET1 to ET5) respectively, leading to a total charge of $3.4 \pm 0.5$, in agreement with the expected value of +3 . The anionic layer is also formed by isolated $\left[\mathrm{Fe}\left(\mathrm{C}_{5} \mathrm{O}_{5}\right)_{3}\right]^{3-}$ anions, although the anions are disposed in double rows along the $c$ axis (one with $\Delta$ and the other with $\Lambda$ chirality, giving also rise to a non chiral structure, Fig. 2b). In contrast to $\mathbf{1}$, the inversion centre in $\mathbf{2}$ is located above the chains and does not impose different orientations of the ET molecules in consecutive ET stacks (Fig. 2b).

Salt $\mathbf{1}$ is a semiconductor with a high room temperature conductivity ( $c a .6 \mathrm{~S} \mathrm{~cm}^{-1}$ and an activation energy of $116 \mathrm{meV}$ ). Salt 2 also presents a high room temperature conductivity ( $c a$. $10 \mathrm{~S} \mathrm{~cm}^{-1}$ ) but shows a metallic behaviour from room temperature down to $c a .140 \mathrm{~K}$, where a broad minimum in the resistivity plot can be observed (Fig. 3 (up)). Below this temperature the conductivity becomes thermally activated but the Arrhenius plot
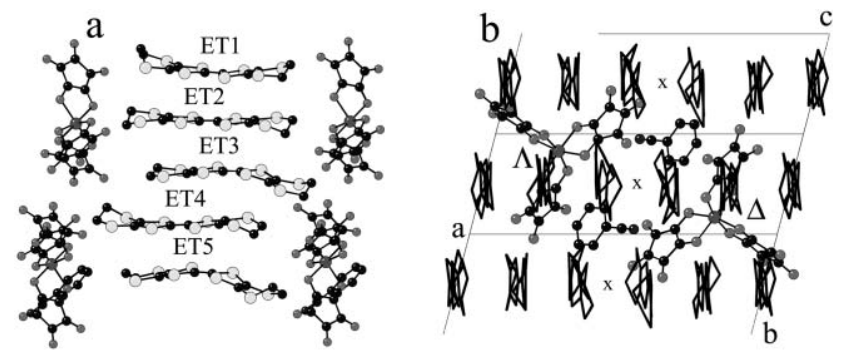

Fig. 2 Structure of 2: (a) View of the alternating cationic and anionic layers. (b) View of the ET layer showing the $\beta$ packing and the anionic layer below. The crosses indicate the locations of the inversion centres in the inorganic layer.
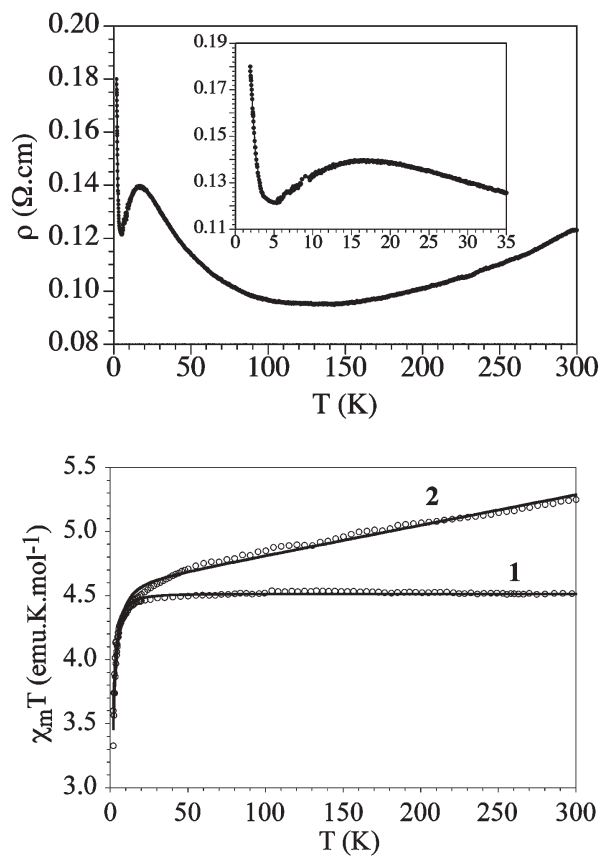

Fig. 3 (up) Thermal variation of the DC resistivity for 2 . Inset; the low temperature region (down) thermal variation of the $\chi_{\mathrm{m}} T$ product for salts 1 and 2. Solid lines represent the best fit to the model (see text).

(Ln $\rho$ vs. 1/T) shows a continuous change in the slope, suggesting the presence of a charge localization starting at $c a$. $140 \mathrm{~K}$ (also observed in the ESR spectra, see below). Below ca. $20 \mathrm{~K}$ the resistivity shows a re-entrance to the metallic state followed by a transition at $c a .7 \mathrm{~K}$ to a semiconducting regime with a low activation energy of $0.5 \mathrm{meV}$. The ESR spectra of both salts show a single line at room temperature with $g$ values of $\approx 2.004$ and a line width $(\Delta H)$ of $c a .80 \mathrm{G}$ that can be attributed to the BEDTTTF donors with some contribution from the $\left[\mathrm{Fe}\left(\mathrm{C}_{5} \mathrm{O}_{5}\right)_{3}\right]^{3-}$ anions. When lowering the temperature the area of this feature (proportional to the spin susceptibility) shows an increase and a maximum at $c a .150 \mathrm{~K}$ followed by a rapid decrease in both salts, suggesting the presence of a charge localization, similar to that observed in some related ET salts of the $\left[\mathrm{Fe}\left(\mathrm{C}_{2} \mathrm{O}_{4}\right)_{3}\right]^{3-}$ anion. $^{3}$

The thermal variation of the molar magnetic susceptibility times the temperature $\left(\chi_{\mathrm{m}} T\right)$ for $\mathbf{1}$ shows a room temperature value of $c a$. $4.5 \mathrm{emu} \mathrm{K} \mathrm{mol}^{-1}$ that remains constant down to $c a$. $15 \mathrm{~K}$ where it shows an abrupt decrease, due to the zero field splitting (ZFS) of the $S=5 / 2 \mathrm{Fe}^{\mathrm{III}}$ ion and/or to very weak antiferromagnetic interactions of dipolar nature (Fig. 3 (down)). In salt 2 the magnetic behaviour is very similar although there is an extra linear contribution corresponding to a temperature independent Paulilike paramagnetism, typical of metallic systems (Fig. 3 (down)). Thus, the magnetic behaviour of both salts can be very well reproduced with a very simple model for an $S=5 / 2$ ion with a ZFS for both salts, ${ }^{12}$ including an independent paramagnetic term $(N \alpha)$ for salt 2, with the following set of parameters: $g=2.0317(4)$ and $|D|=2.15(2) \mathrm{cm}^{-1}$ for salt $\mathbf{1}$ and $g=2.045(2),|D|=$ $2.85(6) \mathrm{cm}^{-1}$ and $N \alpha=2.37(5) \cdot 10^{-3} \mathrm{emu} \mathrm{mol}^{-1}$ for salt 2 (similar to those found in many other metallic radical salts with TTF-type donors $)^{13}$ (solid lines in Fig. 3b). Note that the sign of $D$ cannot be determined from powder measurements and the $D$ value may also include a weak antiferromagnetic coupling between the $\mathrm{Fe}^{\mathrm{III}}$ ions. 
The band structure for $\mathbf{1}$ suggests that the donor lattice must be described as a series of trimeric (ET2-ET3-ET2) ${ }^{3+}$ units and neutral ET1, in agreement with the structural analysis. The direct interaction between these trimeric units, though not negligible, is definitely not strong because the pertinent orbital associated with the electron hopping is now delocalized over the three donors, and thus, the trimer-trimer interaction is smaller than when dealing with single donors. This leads to a localized regime and activated, even if relatively high, conductivity. The band structure for $\mathbf{2}$ contains two partially filled narrow bands (mainly based on the ET4 HOMOs) suggesting a borderline situation between the localized and delocalized regimes, thus providing a rationale for the conductivity results. The structural reason for the band narrowness is the small interaction between ET4 HOMOs through other donors because of the mismatch in the site energies as a result of the strong dimerization of ET1 and ET2 and the formal neutrality of ET3 and ET5.

In conclusion, by using the paramagnetic and chiral anion $\left[\mathrm{Fe}\left(\mathrm{C}_{5} \mathrm{O}_{5}\right)_{3}\right]^{3-}$ with the ET donor, two novel salts with $5: 1$ stoichiometries and peculiar structural and physical properties have been obtained: $\alpha-\mathrm{ET}_{5}\left[\mathrm{Fe}\left(\mathrm{C}_{5} \mathrm{O}_{5}\right)_{3}\right] \cdot 5 \mathrm{H}_{2} \mathrm{O} \quad$ (1) and $\beta-\mathrm{ET}_{5}\left[\mathrm{Fe}\left(\mathrm{C}_{5} \mathrm{O}_{5}\right)_{3}\right] \cdot \mathrm{C}_{6} \mathrm{H}_{5} \mathrm{CN}$ (2). Salt $\mathbf{1}$ is the first example of a chirality-induced $\alpha$ phase and the only known $\theta_{51}$ phase. Salt $\mathbf{2}$ is one of the scarce examples of paramagnetic molecular metals and the only known example out of the tris(oxalate)metalate and tetrahalometalate series. ${ }^{1}$ We are now investigating some modifications of these compounds as the change of the trivalent metal atom (by $\mathrm{Cr}, \mathrm{Co}, \mathrm{Mn}, . .$. ), the use of enantiomeric pure forms of the anions, the substitution of one or more oxygen atoms by sulfur atoms in the croconate ligand and the use of divalent paramagnetic metal atoms to induce the formation of extended anionic lattices.

We acknowledge financial support from the European Union (COST action D35-0011-05 and MAGMANet network of excellence), the Spanish Ministerio de Educación y Ciencia (Projects MAT2004-03849 and BFM2003-03372-C03), Generalitat de Catalunya (2005 SGR 683) and Generalitat Valenciana.

\section{Notes and references}

$\dagger$ Black prismatic crystals of $\alpha-\mathrm{ET}_{5}\left[\mathrm{Fe}\left(\mathrm{C}_{5} \mathrm{O}_{5}\right)_{3}\right] \cdot 5 \mathrm{H}_{2} \mathrm{O}(\mathbf{1})$ and black needlelike crystals of $\beta-\mathrm{ET}_{5}\left[\mathrm{Fe}\left(\mathrm{C}_{5} \mathrm{O}_{5}\right)_{3}\right] \cdot \mathrm{C}_{6} \mathrm{H}_{5} \mathrm{CN}(2)$ were prepared by using the electrocrystallization technique ${ }^{13}$ and very similar conditions: ET (11.34 and $10.70 \mathrm{mg}$ for $\mathbf{1}$ and $\mathbf{2}$, respectively) was placed in the anode chamber of the electrocrystallization cell. $\left(\mathrm{NBu}_{4}\right)_{3}\left[\mathrm{Fe}\left(\mathrm{C}_{5} \mathrm{O}_{5}\right)_{3}\right](240.0$ and $120.0 \mathrm{mg}$, for 1 and 2, respectively) was dissolved in $20 \mathrm{~mL}$ of benzonitrile and this solution was divided into the anode and cathode compartments. The crystals were grown on a platinum wire electrode applying a current density of $1 \mu \mathrm{A} \mathrm{cm}^{-2}$ for a period of 60 days (for 1 ) and 36 days (for 2). Note that although the synthesis conditions are very similar, the obtaining of two different phases is quite common in the radical salts of the ET donor. ${ }^{13}$ In the present case, the increase in the $\mathrm{Fe}(\mathrm{III})$ concentration used for $\mathbf{1}$ has unexpectedly led to the same $5: 1$ stoichiometry, although in the anionic layer the $\left[\mathrm{Fe}\left(\mathrm{C}_{5} \mathrm{O}_{5}\right)_{3}\right]^{3-}$ anions are closer, presumably due to the higher concentration of $\left[\mathrm{Fe}\left(\mathrm{C}_{5} \mathrm{O}_{5}\right)_{3}\right]^{3-}$ anions in the crystallization solution.

* Crystal data for 1: $\mathrm{C}_{65} \mathrm{H}_{50} \mathrm{FeO}_{20} \mathrm{~S}_{40}, M_{\mathrm{r}}=2489.30$, monoclinic, space group $C 2 / c, a=42.4125(5) \AA, b=11.2100(3) \AA, c=20.4336(3) \AA$, $\beta=114.8929(10)^{\circ}, V=8812.5(3) \AA^{3}, Z=4, T=150(2) \mathrm{K}, \rho_{\text {calcd }}=$ $1.876 \mathrm{~g} \mathrm{~cm}^{-3}, \mu(\mathrm{MoK} \alpha)=1.189 \mathrm{~mm}^{-1}$. Of 21290 measured reflections, 10937 were independent and used to refine 574 parameters and 2 restraints. Nonius Kappa CCD diffractometer $\left(4.6^{\circ}<2 \theta<56.6^{\circ}\right)$, crystal size: $0.20 \times 0.10 \times 0.05 \mathrm{~mm}^{3}$. No absorption correction was performed. All non-hydrogen atoms were refined anisotropically. The positions of the $\mathrm{H}$ atoms on the $\mathrm{C}$ atoms were added into the calculated positions and refined with a riding model. The $\mathrm{H}$ atoms of the water molecules were not located. Final $R(I>2 \sigma(I)), R_{1}=0.0466, w R_{2}=0.1104$; final $R$ (all data), $R_{1}=0.1036, w R_{2}=0.1327$. Max./min. residual electron density $1.066 /$ $-0.584 \mathrm{e}^{-3}$. Crystal data for $2: \mathrm{C}_{72} \mathrm{H}_{45} \mathrm{FeNO}_{15} \mathrm{~S}_{40}, M_{\mathrm{r}}=2502.34$, triclinic space group $P-1, a=19.591(2) \AA, b=19.395(2) \AA, c=12.9581$ (12) $\AA, \alpha=$ $103.194(11)^{\circ}, \beta=102.859(11)^{\circ}, \gamma=73.680(10)^{\circ}, V=4534.1(8) \AA^{3}, Z=2$, $T=170 \mathrm{~K}, \rho_{\text {calcd }}=1.833 \mathrm{~g} \mathrm{~cm}^{-3}, \mu(\operatorname{MoK} \alpha)=1.153 \mathrm{~mm}^{-1}$. Of 33942 collected reflections , 12379 were independent. Stoe IPDS diffractometer $\left(4.4^{\circ}<2 \theta<51.8^{\circ}\right)$, crystal size: $0.75 \times 0.375 \times 0.075 \mathrm{~mm}^{3}$. Final $R(I>$ $2 \sigma(I)), R_{1}=0.0528, w R_{2}=0.0745$; final $R$ (all data), $R_{1}=0.1119, w R_{2}=$ 0.2029 . Max./min. residual electron density $0.467 /-0.465$ e $\AA^{-3}$. Structures 1 and 2 were solved and refined using full-matrix least squares on $F^{2}$ using the WINGX package programs. ${ }^{14}$ CCDC 294531 and 269569. For crystallographic data in CIF or other electronic format see DOI: $10.1039 / \mathrm{b} 610408 \mathrm{~h}$

$\S$ Variable temperature susceptibility measurements were carried out in the temperature range 2-300 $\mathrm{K}$ with an applied magnetic field of $1 \mathrm{~T}$ on polycrystalline samples of $\mathbf{1}$ and $\mathbf{2}$ with a Quantum Design MPMS-XL-5 SQUID magnetometer.

- D.C. conductivity measurements over the range $2-300 \mathrm{~K}$ were performed with the four contacts method for several crystals of both salts, giving reproducible results in all the samples. The samples were measured in a Quantum Design PPMS-9.

|| The tight-binding band structure calculations used an extended Hückel hamiltonian with exponents and parameters taken from previous work. ${ }^{15}$

1 E. Coronado and P. Day, Chem. Rev., 2004, 104, 5419; T. Enoki and A. Miyazaki, Chem. Rev., 2004, 104, 5449; H. Kobayashi, H. B. Cui and A. Kobayashi, Chem. Rev., 2004, 104, 5265; E. Coronado and J. R. Galán-Mascarós, J. Mater. Chem., 2005, 15, 66.

2 M. Kurmoo, A. W. Graham, P. Day, S. J. Coles, M. B. Hursthouse, J. L. Caulfield, J. Singleton, F. L. Pratt, W. Hayes, L. Ducasse and P. Guionneau, J. Am. Chem. Soc., 1995, 117, 12209; L. Martin, S. S. Turner, P. Day, F. E. Mabbs and E. J. L. McInnes, Chem. Commun., 1997, 1367; S. Rashid, S. S. Turner, P. Day, J. A. K. Howard, P. Guionneau, E. J. L. McInnes, F. E. Mabbs, R. J. H. Clark, S. Firth and T. Biggs, J. Mater. Chem., 2001, 11, 2095.

3 E. Coronado, S. Curreli, C. Giménez-Saiz and C. J. Gómez-García, J. Mater. Chem., 2005, 15, 1429; E. Coronado, S. Curreli, C. GiménezSaiz and C. J. Gómez-García, Synth. Met., 2005, 154, 245.

4 E. Coronado, J. R. Galán-Mascarós, C. J. Gómez-García and V. N. Laukhin, Nature, 2000, 408, 447; A. Alberola, E. Coronado, J. R. Galán-Mascarós, C. Giménez-Saiz and C. J. Gómez-García, J. Am. Chem. Soc., 2003, 125, 10774; E. Coronado, J. R. Galán-Mascarós, C. J. Gómez-García, E. Martínez-Ferrero and S. Van Smaalen, Inorg. Chem., 2004, 43, 4808.

5 S. Uji, H. Shinagawa, T. Terashima, T. Yakabe, Y. Terai, M. Tokumoto, A. Kobayashi, H. Tanaka and H. Kobayashi, Nature, 2001, 410, 908.

6 M. L. Calatayud, J. Sletten, M. Julve and I. Castro, J. Mol. Struct., 2005, 741, 121

7 S. Curreli, P. Deplano, C. Faulmann, M. L. Mercuri, L. Pilia, A. Serpe, E. Coronado and C. J. Gómez-García, Inorg. Chim. Acta, 2006, 359, 1177 .

8 T. Mori, H. Mori and S. Tanaka, Bull. Chem. Soc. Jpn., 1999, 72, 179.

9 P. Guionneau, C. J. Kepert, G. Bravic, D. Chasseau, M. R. Truter, M. Kurmoo and P. Day, Synth. Met., 1997, 86, 1973.

10 E. Coronado, C. Giménez-Saiz and C. J. Gómez-García, Coord. Chem. Rev., 2005, 249, 1776; E. Coronado, S. Curreli, C. Giménez-Saiz, C. J. Gómez-García and J. Roth, Synth. Met., 2005, 154, 241.

11 T. Mori, Bull. Chem. Soc. Jpn., 1998, 71, 2509.

12 C. J. O'Connor, Prog. Inorg. Chem., 1982, 29, 203.

13 J. M. Williams, J. R. Ferraro, R. J. Thorn, K. D. Carlson, U. Geiger, H. H. Wang, A. M. Kini and M. H. Whangbo, Organic Superconductors: Synthesis, Structure, Properties and Theory, ed. R. N. Crimes, Prentice Hall, Englewood Cliffs, NJ, 1992.

14 L. J. Farrugia, J. Appl. Crystallogr., 1999, 32, 837.

15 M.-H. Whangbo and R. Hoffmann, J. Am. Chem. Soc., 1978, 100, 6093; A. Pénicaud, K. Boubekeur, P. Batail, E. Canadell, P. Auban-Senzier and D. Jérome, J. Am. Chem. Soc., 1993, 115, 4101. 